\title{
Development and Local Contextualization of Mobile Health Messages for Enhancing Disease Management Among Community-Dwelling Stroke Patients in Rural China: Multimethod Study
}

Enying Gong ${ }^{1,2^{*}}$, MSc; Wanbing Gu ${ }^{1 *}$, MSc; Erdan Luo ${ }^{1,3}$, MSc; Liwei Tan ${ }^{1,4}$, MSc; Julian Donovan ${ }^{5}$ MD; Cheng Sun $^{1}$, PhD; Ying Yang ${ }^{1}$, MSc; Longkai Zang ${ }^{1,6}$, BSc; Peng Bao ${ }^{1,7}$, MBBS; Lijing L Yan ${ }^{1,8}$, PhD, MPH

${ }^{1}$ Global Health Research Center, Duke Kunshan University, Kunshan, China

${ }^{2}$ School of Population and Global Health, The University of Melbourne, Melbourne, Australia

${ }^{3}$ Institute of Chinese Medical Sciences, University of Macau, Taipa, Macau, China

${ }^{4}$ School of Public Health, Fudan University, Shanghai, China

${ }^{5}$ Northumbria Healthcare National Health Service Foundation Trust, Wallsend, United Kingdom

${ }^{6}$ Second School of Clinical Medicine, Wuhan University, Wuhan, China

${ }^{7}$ Ningxia Medical University, Yinchuan, China

${ }^{8}$ Duke Global Health Institute, Durham, NC, United States

* these authors contributed equally

\section{Corresponding Author:}

Lijing L Yan, PhD, MPH

Global Health Research Center, Duke Kunshan University

No 8 Duke Road

Kunshan,

China

Phone: 8651236657057

Email: lijing.yan@dukekunshan.edu.cn

\section{Abstract}

Background: Rural China has experienced an increasing health burden because of stroke. Stroke patients in rural communities have relatively poor awareness of and adherence to evidence-based secondary prevention and self-management of stroke. Mobile technology represents an innovative way to influence patient behaviors and improve their self-management.

Objective: This study is part of the System-Integrated Technology-Enabled Model of Care (the SINEMA trial) to improve the health of stroke patients in resource-poor settings in China. This study aimed to develop and pilot-test a mobile phone message-based package, as a component of the SINEMA intervention.

Methods: The SINEMA trial was conducted in Nanhe County, Hebei Province, China. A total of 4 villages were selected for pretrial contextual research and pilot study. The 5 stages for developing the mobile phone messages were as follows: (1) conducting literature review on existing message banks and analyzing the characteristics of these banks; (2) interviewing stroke patients and caregivers to identify their needs; (3) drafting message contents and designing dispatching algorithms for a 3-month pilot testing; (4) collecting feedback from pilot participants through questionnaire survey and in-depth interviews on facilitators and barriers related to their acceptance and understanding of messages; and (5) finalizing the message-based intervention based on participants' feedback for the SINEMA trial.

Results: On the basis of 5 existing message banks screened out of 120 papers and patients' needs identified from 32 in-depth interviews among stroke patients and caregivers, we developed a message bank containing 224 messages for a pilot study among 54 community-dwelling stroke patients from 4 villages. Of 54 participants, 51 (response rate: 94.4\%) completed the feedback survey after receiving daily messages for 3 months. Participants' mean age was 68 years (SD 9.2), and about half had never been to school. We observed a higher proportion of participants who were in favor of voice messages $(23 / 42,54 \%)$ than text messages $(14 / 40,35 \%)$. Among participants who received voice messages $(n=43)$ and text messages $(n=40)$, 41 and 30 , respectively, self-reported a full or partial understanding of the contents, and $39(39 / 43,91 \%)$ and $32(32 / 40,80 \%)$, respectively, rated the 
messages as helpful. Analyses of the 32 interviews further revealed that voice messages containing simple and single-theme content, in plain language, with a repeated structure, a slow playback speed, and recorded in local dialect, were preferred by rural stroke patients. In addition, the dispatching algorithm and tools may also influence the acceptance of message-based interventions.

Conclusions: By applying multiple methodologies and conducting a pilot study, we designed and fine-tuned a voice message-based intervention package for promoting secondary prevention among community-dwelling stroke patients in rural China. Design of the content and dispatching algorithm should engage both experts and end users and adequately consider the needs and preferences of recipients.

(JMIR Mhealth Uhealth 2019;7(12):e15758) doi: $\underline{10.2196 / 15758}$

\section{KEYWORDS}

phone messages; stroke; secondary prevention; rural population; China

\section{Introduction}

\section{Stroke Secondary Prevention in Rural China}

Stroke is the leading cause of death and disability in China. According to recent estimates, stroke-related deaths reached around 1.1 million in China, accounting for $23 \%$ of total deaths in rural areas and $21 \%$ in urban areas [1]. In addition, it is estimated that there are 12.4 million stroke patients aged older than 40 years living in China, which causes an enormous burden to the health care system and society [2]. Compared with urban areas, rural China has experienced a more rapidly increasing burden, with the age-standardized prevalence of stroke increasing 2.5-fold over the past three decades [3].

Stroke patients in rural areas have relatively low awareness of and poor adherence to the secondary prevention and self-management of stroke. Effective secondary prevention of stroke, including lifestyle modification and a combination of medical therapy (eg, antiplatelet, antilipid, and antihypertensive therapy), has been well studied as the best buy for stroke patients [4]. However, adherence to these effective preventive strategies is poor among stroke patients, with more than half of patients reported discontinuing their secondary prevention medications within 3 months of hospital discharge [5,6]. In addition, the fragmented primary health care system and limited capacities of health care providers in rural China further restrain the availability and quality of the health care services that stroke patients can gain access to [7]. Therefore, there is an urgent need to develop a low-cost and effective strategy to increase the awareness of and adherence to secondary prevention measures of stroke in rural China.

\section{Message-Based Intervention}

With the development of mobile communication technology and widespread adoption of mobile phones, mobile health (mHealth) has the potential to empower patients to improve their self-management of chronic conditions and related risk factors [8,9]. A previous literature review illustrated that compared with high-income countries where more advanced mobile technologies are used, low- and middle-income countries have relied more on phone messages for intervention delivery because of its accessibility, lower cost, and better acceptance [10]. Review studies and meta-analysis have illustrated the modest effect of message-based interventions in promoting medication adherence and lifestyle modifications and improving health outcomes among patients with chronic conditions, although further studies with longer follow-up period and larger scale were suggested $[8,9]$. The evidence on message-based studies targeted at stroke patients was very limited, with a few studies focused on recently discharged stroke patients [11], but almost none on community-dwelling patients. In addition, there were only a few studies that tried to understand the feasibility and impact of message-based interventions among patients with cardiovascular diseases in China, and most of these studies focused on urban patients [12]. The acceptability and feasibility of applying message-based interventions among rural patients still need to be further investigated.

In addition, some of the previous reviews attempted to examine why some of the message-based interventions work or do not work. Factors related to message contents and dispatching algorithms, such as message frequency, content personalization, and dispatching approach in 2 ways, were examined, but the results were mixed $[13,14]$. Studies also pointed out that lacking theoretical constructs may lead to the difficulty in understanding the mechanisms behind the message-based interventions in chronic disease management. Watkins et al conducted a realist review by mapping the intervention components with psychological theories and frameworks [15]. The authors found that information provided via messages to increase patients' knowledge could motivate patients to believe the relevance of the issue to their health and the potential risk, which may reduce the threat as suggested by the health belief model [16]. Some other psychological behavior change theories, such as the transtheoretical model or a taxonomy model of behavior change techniques, including goal settings and self-regulation, were also applied in the design of messages [15,17].

\section{Objectives}

This study is part of the System-Integrated Technology-Enabled Model of Care (the SINEMA trial) to improve the health of stroke patients in resource-poor settings in China. The protocol of the SINEMA trial has already been published [18]. This study aimed to describe the development and contextualization process of this message-based intervention package from field-based research and pilot studies. The results of the effectiveness of the message-based intervention in the SINEMA main trial is beyond the scope of this paper. 


\section{Methods}

\section{Study Setting}

The SINEMA trial and this pilot study were conducted in Nanhe County, Hebei Province, China, with an intention to be adapted to other resource-limited settings. Nanhe County is an economically poor provincial county with an annual disposable income per capita of 11,030 RMB (less than half of the national average) [19]. Although no specific estimation on stroke burden is available in this county, previous studies have shown a high burden of stroke in this province and rural settings compared with other parts of China [20].

To ensure the study design and blind generalization of the intervention model, we aimed to identify 4 villages out of 218 villages within the geographical area to implement the field-based contextual research and pilot study, and these 4 villages were not eligible to be included in the trial. We received assistance from the local Center for Disease Control and Prevention to identify 4 villages where village doctors were willing to participate. These 4 villages comprised 2 villages from a township that had an insufficient number of villages to

Figure 1. Overview of key stages of message development. be eligible for the main trial and 2 villages from eligible township but with insufficient residents to meet the inclusion criteria of the main trial. Therefore, we were able to identify typical villages but also leave the potential eligible large villages for the main trial.

\section{Message Design Process}

We used multiple methodologies, including literature review, expert consultation, qualitative in-depth interviews, and field-based pilot study followed by surveys and interviews, in developing the messages to ensure that the message contents were built based on research evidence and in line with the clinical guidelines and were suitable for the local context. The development process for the mobile phone message banks consisted of the following 5 stages: (1) conducting a literature review on existing message banks targeting people with stroke, (2) interviewing stakeholders to identify the needs of stroke patients, (3) creating and designing the message contents and message sending algorithm, (4) conducting pilot testing of the messages among patients in 4 villages, and (5) refining and finalizing the message bank and sending algorithm based on the lessons learned from the pilot study. Figure 1 outlines the design process.

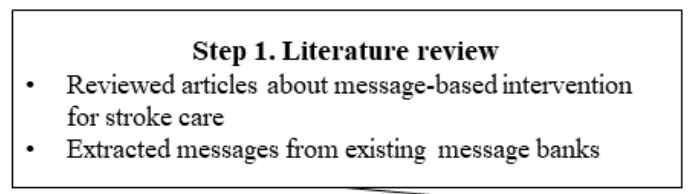

\begin{tabular}{l}
\multicolumn{1}{c|}{ Step 2. Contextual research } \\
- Conducted in-depth interviews among stroke patients \\
and caregivers \\
- Analyzed and identified stroke patients' need
\end{tabular}

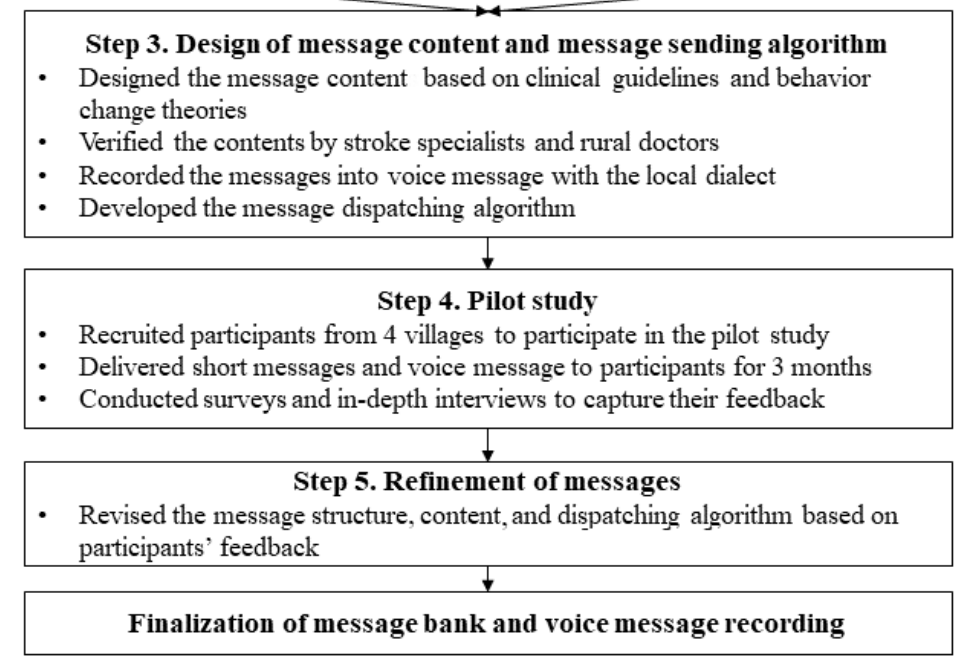

\section{Stage 1. Literature Review on Existing Message Banks}

To assist the design of the message bank, we conducted a literature review based on the PubMed database to search for existing text message banks published between October 1, 2011, and October 1, 2016. Our own design of the messages began in November 2016. Key search terms included stroke and text messages (for search terms and review criteria, see Multimedia
Appendix 1). A total of 2 reviewers screened the searched papers, and a snowball review by reviewing titles and abstracts of references of searched papers was also conducted to increase the scope of the review. Existing message banks were extracted and translated into Chinese as a reference for the design. 


\section{Stage 2. Contextual Research}

To identify the needs of stroke patients, we visited the field 3 times over the period of 5 months from May to September 2016 and conducted in-depth interviews among stakeholders, including stroke patients and family caregivers. Semistructured interview guides were developed, and questions in the interview included patients' health status and needs for managing their conditions. Stroke patients were identified with the assistance of village doctors with the criteria that the participants were aged 18 years or older, had a history of stroke diagnosed at the county- or higher-level hospitals, were in clinically stable condition, had basic communication abilities, and were willing to participate in the study. Stroke patients' family members who were at home while the research team visited and were willing to participate were also interviewed separately. The number of participants interviewed was determined based on the saturation theory, whereby participants were recruited until no further new information was acquired through the interview process. We expect to interview about 4 patients from each village.

\section{Stage 3. Design of Message Content and Message Sending Algorithm}

We designed the contents of messages on the basis of the existing message banks from the literature review, the identified needs of stroke patients from contextual research, and the behavior change theories such as the health belief model and the transtheoretical model [16,21]. First, the structure and focus of the message bank were identified so that messages could tap into key dimensions based on patients' needs. We then grouped the existing messages into 6 categories based on their contents, including management of metabolic risk factors, medication adherence, tobacco and alcohol control, dietary change, exercise and rehabilitation, and psychological support. The content of the messages was modified to be suitable for stroke patients in rural China. The messages were then verified by stroke specialists working in tertiary hospitals and recorded in the local dialect.

We also designed the message dispatching algorithm by setting the sending time and frequency based on the daily habits of stroke patients. This algorithm was linked with a digital health management system that was designed to support the delivery of the digital health components of SINEMA intervention.

\section{Stage 4. Pilot Study}

A pilot study was conducted in 4 villages to test the SINEMA intervention model, including the acceptance of the message-based intervention among stroke patients. Participants who were aged older than 18 years, had a history of stroke but in a clinically stable condition, and able to communicate via mobile phone were eligible to participate in the study. In each village, village doctors screened stroke patients in their villages and provided the list to the study team. Participants were invited by village doctors and recruited by the research team. Before the commencement of the pilot study, a structured questionnaire, including questions on participants' demographic characteristics and disease history, designed based on previous studies [22,23], was administered by the research team through face-to-face interviews.
During the 3-month pilot study, participants and their caregivers received text messages at 3 pm every 2 days, and the participants also received voice messages with the same content at $7 \mathrm{pm}$ on alternating days when they did not receive the text messages. At the end of the pilot study, participants completed a short questionnaire administered by their village doctors. Questions in the survey included whether they had read or listened to the messages, their understanding of the contents of the messages, and their perspectives on the helpfulness of these messages. In-depth interviews were also conducted by the research team among selected participants to seek detailed feedback.

\section{Stage 5. Refinement of the Messages}

After the pilot study, the research team summarized the feedback from participants and refined the message contents and message dispatching algorithm. To optimize the acceptance and understanding of the messages, the research team revised the language in each message based on participants' feedback and preference. Village doctors and physicians from county hospitals were invited to verify the messages to ensure that local contexts were taken into full consideration, and the terms used in the messages were understandable by the target population.

\section{Data Analysis}

To apply the interview results to message development, we analyzed the interview transcripts using thematic analysis approach, which is a method for identifying, analyzing, and reporting patterns within data and is able to both reflect the reality and explain the undersurface meaning [24]. Following the thematic analysis approach, we conducted the following steps: the research team first read the transcripts of the interviews to be familiar with the data, then generated the key concepts for coding based on the interview guide. Data were coded line by line and grouped into categories using NVivo 11 software (QSR International). Each category of coding was then further reviewed and examined. The groups of key themes were refined before finalizing the major themes. Discussions within the research team were organized after each key step to ensure the trustworthiness and define the final themes. Quotations used in this paper were translated from Chinese to English and then back translated into Chinese to increase the accuracy of the interpretation.

A descriptive analysis was conducted for survey data. Continuous variables were reported as mean and SD if normally distributed or as median with 25th and 75th percentiles if not. Counts and proportions were reported for categorical variables. Survey data were analyzed using STATA software (version 15; StataCorp LLC).

\section{Ethical Considerations}

All research activities, including both contextual research and pilot study, were approved by the institutional review board of Duke Kunshan University. All participants in the study provided informed consent before taking part in the study. 


\section{Results}

\section{Summary}

In this section, we first describe the main findings from stages 1, 2, and 4 explained above: the literature review, contextual research, and the pilot study. We then describe how we developed and refined the message bank based on these findings (stages 3 and 5). Finally, we briefly introduce the actual -message-based intervention adopted in the trial.

\section{Message Bank Review and Extraction}

After the systematic search and snowball review of cited papers, we found 5 existing SMS banks. Using these 5 completed SMS banks, we translated messages into Chinese, resulting in a total of 224 messages as the basis for further design. Multimedia Appendix 1 shows the Preferred Reporting Items for Systematic Reviews and Meta-Analyses diagram of the literature review and the contents and features of these 5 identified message banks.

\section{Results From Contextual Research on Stroke Patients' Needs}

During the 3 contextual research visits, we interviewed 22 stroke patients and 10 caregivers. Through analyses of these interviews, we identified the major needs of patients and the required contents of messages.

\section{Content 1: General Knowledge About Stroke Secondary Prevention}

Although almost all patients involved in the interview expressed a strong desire to recover from stroke, most of them had limited awareness and knowledge of secondary prevention of stroke, which was insufficient and not comprehensive enough to help them overcome all challenges that they faced in managing their conditions. There were very few sources available to patients regarding evidence-based information related to stroke secondary prevention:

\section{No physicians told us what we should pay attention to when I was in the hospital. They [physicians] did not care about it. Only the village doctor told us some [information]. [Patient \#8]}

Village doctors, considered as the key source of information and the first contact of care, also had the minimal capacity to provide intensive health education to patients because of their existing high workload of serving more than 1000 residents in the village. Therefore, general knowledge related to stroke secondary prevention was required in the message bank.

\section{Content 2: Promoting Adherence to Guideline-Recommended Activities}

In the interview, many patients admitted that they were not able to adhere to all secondary prevention medications. The main reasons for nonadherence to medication use included their forgetfulness because of declining memory, impaired mental function, or busy working lives. We found that most of the patients we interviewed lived alone or with their spouse alone, without any other caregivers to remind them to take their medications:
I often forgot to take medicine. He [the patient's husband] usually put all the medicines on my table and reminded me to take them...If he also forgot, we would forget about it totally. [Patient \#11]

Considering the lack of reminders and the suboptimal adherence among most stroke patients, we decided that the message should act as a reminder for patients to promote their adherence to treatment.

\section{Content 3: Providing Specific Guidance on Recommendations for Physical Activity}

Through the interview, we also found that, even for people who were aware of the importance of stroke secondary prevention, they had little knowledge of how to perform physical activities or rehabilitation. For example, almost no patients knew the proper frequency and intensity of physical activities that they should achieve, nor the strategies to protect themselves from injury during exercise. In addition, walking was the most common way of exercise for most patients involved in the interview, and few patients knew how to train their upper limbs in their physical activities to promote their recovery of daily functions:

\section{He [the physician] just told me to walk more. [Patient \#2] \\ I do not have other forms of exercise. I just walk for a while every morning in the village...I usually sit or sleep at home for most of the remaining day. [Patient \#4]}

Therefore, we believe that providing more tips and guidance on how to undertake the guideline-recommended physical activity and rehabilitation will match the needs of stroke patients.

\section{Results From the Pilot Study}

A total of 54 stroke patients from 4 villages in 2 townships in Nanhe County participated in the pilot study from February to May 2017. Among them, 51 participants (response rate: 94.4\%) completed the feedback survey after the pilot study. Table 1 shows the characteristics of the participants. The average age of participants was 68.0 years (SD 9.2). Most of them were males $(33 / 51,65 \%)$, aged older than 65 years $(33 / 51,53 \%)$, married $(40 / 51,78 \%)$, with no education or having never graduated from primary school $(27 / 51,53 \%)$, had suffered ischemic stroke $(45 / 51,88 \%)$, and experienced more than 1 stroke event $(31 / 51,61 \%)$.

Among participants who responded to the feedback survey, 40 $(40 / 51,78 \%)$ and $43(43 / 51,84 \%)$ stated that they had successfully received text messages or voice messages during the pilot study, respectively. Table 2 shows the self-reported acceptance and understanding of messages for these participants. We observed a higher proportion of participants who were in favor of voice messages: $54 \%$ (23/43) of participants listened to the voice messages all the time, whereas only $35 \%(14 / 40)$ of participants self-reported their frequent text-message reading. Of 43 participants, 41 (95\%) who listened to the voice messages self-reported that they could understand the content entirely or partially, whereas 30 of 41 (75\%) participants reported that they 
were able to fully or partially understand the contents in the text messages. In addition, 39 of $43(91 \%)$ participants who had ever received voice messages and 32 of $40(80 \%)$ participants who had ever received text messages rated that the messages were helpful. In addition, 27 participants reported that their family caregivers had received text messages, and 11 of them reported that their family members had read the messages to them.

Table 1. Demographic characteristics and disease history of participants who responded to the feedback survey (N=51).

\begin{tabular}{|c|c|}
\hline Characteristics & $\mathrm{n}(\%)$ \\
\hline \multicolumn{2}{|l|}{ Demographic characteristics } \\
\hline \multicolumn{2}{|l|}{ Gender } \\
\hline Male & $33(65)$ \\
\hline Female & $18(35)$ \\
\hline \multicolumn{2}{|l|}{ Age group (years) } \\
\hline$\geq 65$ & $33(65)$ \\
\hline$<65$ & $18(35)$ \\
\hline \multicolumn{2}{|l|}{ Marital status } \\
\hline Married & $40(78)$ \\
\hline Divorced, widowed, or unmarried & $11(22)$ \\
\hline \multicolumn{2}{|l|}{ Education } \\
\hline Never been to school & $22(43)$ \\
\hline Less than primary school & $5(10)$ \\
\hline Primary school & $10(20)$ \\
\hline Primary high school & $10(20)$ \\
\hline High school and above & $4(8)$ \\
\hline \multicolumn{2}{|l|}{ Occupation } \\
\hline Unemployed & $7(14)$ \\
\hline Self-employed including doing farm work & $39(77)$ \\
\hline Employed & $4(8)$ \\
\hline Others & $1(2)$ \\
\hline \multicolumn{2}{|l|}{ Main caregiver } \\
\hline Spouse & $35(69)$ \\
\hline Children & $7(14)$ \\
\hline Others & $9(18)$ \\
\hline \multicolumn{2}{|l|}{ Disease history } \\
\hline \multicolumn{2}{|l|}{ Stroke type } \\
\hline Ischemic stroke & $45(88)$ \\
\hline Hemorrhage stroke & $5(10)$ \\
\hline Cannot remember & $1(2)$ \\
\hline \multicolumn{2}{|l|}{ Suffered more than 1 stroke event } \\
\hline Yes & $31(61)$ \\
\hline No & 20 (39) \\
\hline
\end{tabular}


Table 2. Participants' acceptance and perceptions of voice messages and text messages (of 54 participants, 51 completed the feedback survey, 40 responded that they had received text messages, and 43 responded that they had received voice messages).

\begin{tabular}{|c|c|c|}
\hline Acceptance and perception & Voice messages $(\mathrm{N}=43), \mathrm{n}(\%)$ & Text messages $(\mathrm{N}=40), \mathrm{n}(\%)$ \\
\hline \multicolumn{3}{|c|}{ The frequency of reading/listening to the entire message } \\
\hline All the time & $23(54)$ & $14(35)$ \\
\hline Sometime & $20(47)$ & $14(35)$ \\
\hline Never & $0(0)$ & $12(30)$ \\
\hline \multicolumn{3}{|c|}{ Level of understanding toward message contents } \\
\hline Entire message & $18(42)$ & $12(30)$ \\
\hline A part of the message & $23(54)$ & $18(45)$ \\
\hline Cannot understand at all & $2(5)$ & $10(25)$ \\
\hline \multicolumn{3}{|c|}{ Whether think the messages were helpful } \\
\hline Yes & $39(91)$ & $32(80)$ \\
\hline No & $3(7)$ & $4(10)$ \\
\hline Do not know & $1(2)$ & $1(3)$ \\
\hline Missing & $-{ }^{\mathrm{a}}$ & $3(8)$ \\
\hline
\end{tabular}

${ }^{a} 3$ participants who received text messages did not respond to this question. No missing values among participants who received voice messages on this question.

\section{Qualitative Results From the Pilot Study}

After the pilot study, we interviewed 8 participants. Their feedback covered a variety of perspectives, including the content of the message, the form, and algorithms of message dispatching, and other barriers related to receiving and understanding the messages. This feedback guided our decision making in optimizing the message contents and sending the algorithm to fit the local context.

\section{Message Contents}

In line with the quantitative results, we also found that not all participants were able to understand the messages fully. Barriers to acceptance included the broad scope and complex content of the information covered in the messages, the relevance of messages toward their health conditions, the complexity of the terms and languages, and their own capacity to read and memorize information.

Many patients told us that they usually had poor memory and would easily forget things. They could usually understand the messages, but they would forget most of the contents after a short while if too much information was covered in a single message:

\section{I could understand the message when I listened to it, but I would forget most of them quickly after I put down my phone. [Patient \#6]}

In addition to the preference for simple information within a message, participants also reported that some terms in the messages were not in plain language, which made the messages more difficult to understand.

In terms of the impact of messages on helping them in managing the risk factors, some of the participants reported that not all the information was relevant to them. For example, messages related to smoking or drinking were only applicable to a small proportion of participants we interviewed:

He [the patient] drank every day before the stroke occurrence, but he quit after it. He doesn't dare to drink anymore. [Spouse of Patient \#2]

\section{Message Dispatch Form and Algorithms}

Almost all patients who participated in the interview showed greater interest in and spoke highly of the voice messages, whereas very few participants reported that they had read text messages. This was mainly because of participants' illiteracy in reading text or their technical capability in checking text messages on the phone:

My child bought a feature phone for me, and I know how to dial or pick up a call...I never read text messages. I am illiterate. [Patient \#2]

Participants also identified the potential factors that may facilitate their acceptance and understanding toward voice messages. Almost all participants involved in the interviews agreed that they preferred messages using the local dialect rather than standard Mandarin. Some of the participants also mentioned that a slower playback speed of the voice messages might improve their understanding of the message contents. In addition, participants recommended repeating the messages or extending the duration of messages so that they could better absorb the information when listening:

\section{Sometimes I was doing my housework when I picked up the phone. She [the voice message] spoke toofast, and the message ended before I could concentrate my mind to listen to it. [Patient \#4]}

In terms of the frequency and timing of message dispatch, most participants said that they were willing to receive the messages daily. In addition, participants suggested that receiving the 
message in the morning would be more helpful, especially for reminding them of taking medicines:

I often forget the medicines I should take in the morning because I usually have housework to do. But I usually can remember to take the medication at night before going to bed. [Patient \#1]

I would like to take the medicines, but I inevitably forget to do it sometimes... It would be, of course, good if someone can remind me every day. [Patient \#2]

\section{Phone Scams}

From our interview, we also found some other factors that may influence the implementation of the message-based intervention. Patients reported that they would reject phone calls from unknown numbers because they were afraid that it could be a phone scam. The numbers used to send the voice messages were different every day at the beginning of the pilot study, so some of the participants were cautious about the messages received and refused to listen to the voice messages. Participants mentioned that it would be easier for them to get the voice messages if the same number was used.

\section{Major Refinement of Messages}

On the basis of the results from the pilot study, we made a series of decisions regarding the contents and dispatching algorithms of the messages to fit the local context and our target population better. Considering the prevalence of illiteracy and poor technical capacity in reading text messages, we decided to only use voice message delivery for the main study. Table 3 summarizes critical points where we optimized the message contents and algorithm.
To increase stroke patients' understanding of the messages, we simplified the themes, structure, and language of each message. We highlighted the focus on medication adherence and physical activities that were appropriate for most stroke patients. Only a small proportion of the total messages were supplemented by general information related to stroke and management of other risk factors. In addition, we further refined each message by retaining only one key piece of information and used the same structure for each message (the program name, followed by a reminder sentence alternating between taking medicine and exercise regularly, and then specific health education information). The application of the health belief model [16] and the transtheoretical model on the stage of change [21] was carefully considered in refining each health education information and the order of messages. Furthermore, we invited physicians in the township hospitals to review all messages and amend any clinical or academic terms into plain language that would be commonly used and understood by the target population. Multimedia Appendix 2 shows some examples of the revised messages.

We also improved the message recording and dispatch algorithm to better suit the preferences of the target population. We continued to record voice messages using the local dialect and selected a slower playback speed, with the message being repeated twice per message delivery. In addition, we decided not to dispatch any text messages but rather send out voice messages daily. We changed the message dispatch time from $7 \mathrm{pm}$ to 7 am so that the messages can better remind patients of medication taking. Furthermore, we optimized our message dispatch system so that a single consistent sender phone number would be displayed on participants' phones. 
Table 3. Comparison of key aspects of message optimization.

\begin{tabular}{|c|c|c|}
\hline Aspects of message optimization & Pilot study & Main study \\
\hline \multicolumn{3}{|l|}{ Message content } \\
\hline Themes & $\begin{array}{l}\text { A broad scope of information, including management } \\
\text { of metabolic risk factors, medication adherence, tobacco } \\
\text { and alcohol control, dietary change, physical activity, } \\
\text { and psychological recovery }\end{array}$ & $\begin{array}{l}\text { Focused on medication adherence and physical activity } \\
\text { and supplemented with other information on metabolic } \\
\text { risk factor management and stroke in general }\end{array}$ \\
\hline Structure & Random structure for each message & $\begin{array}{l}\text { Same structure for all messages: program name }+r e- \\
\text { minder sentence }+ \text { health education information }\end{array}$ \\
\hline Key information & Multiple key information within 1 message & Single key information for 1 message \\
\hline Languages & With some professional terms & Simple plain language \\
\hline Verification & By stroke specialists in first-tier hospitals & By village doctors and township physicians \\
\hline $\begin{array}{l}\text { Health behavior change the- } \\
\text { ory }\end{array}$ & $\begin{array}{l}\text { Health belief model and the transtheoretical model (stage } \\
\text { of change) }\end{array}$ & $\begin{array}{l}\text { Health belief model and the transtheoretical model (stage } \\
\text { of change) }\end{array}$ \\
\hline \multicolumn{3}{|l|}{ Message recording } \\
\hline Speed & Normal speaking speed & Slower than the normal speaking speed \\
\hline Repeating & No repetition & Repeated once \\
\hline Dialect & Local dialect & Local dialect \\
\hline \multicolumn{3}{|l|}{ Message dispatch algorithms } \\
\hline Text message & 3 pm every 2 days & No text message \\
\hline Voice message & 7 pm every 2 days & 7 am every day \\
\hline Receiver & Patients and caregivers & Patients only \\
\hline Senders & Random phone number & Single consistent phone number \\
\hline
\end{tabular}

\section{Messages Delivered Through System-Integrated Technology-Enabled Model of Care Trial}

A message bank containing 92 voice messages was developed to support the SINEMA main trial. These messages were repeated for 4 times to support the year-long intervention. The voice messages had been delivered to more than 600 stroke patients who participated in the SINEMA trial in rural China since July 2017. During the year-long intervention, a total of more than 100,000 messages were sent to participants and some caregivers in the intervention arm if they had a phone and were willing to receive the messages.

\section{Discussion}

\section{Principal Findings}

In this study, we applied a multiple methodological study approach to develop mHealth messages to promote secondary prevention of stroke among community-dwelling stroke patients in rural China. We created the initial messages based on existing message banks from previous studies; involved patients in the initial study design in capturing their needs; evaluated patients' acceptance through a 3-month pilot study, including quantitative surveys and in-depth interviews; and finally, refined and optimized the message contents and dispatching algorithm based on the feedback provided by participants.

This study is one of the few studies that have developed message-based intervention among people with cardiovascular diseases [25] and the first ever for stroke patients in rural China. Our study provides important information to researchers and policy makers about the feasibility of delivering voice message intervention for community-dwelling stroke patients in resource-limited settings. Our study further revealed that voice messages were favored over text messages among stroke patients in rural China, as voice messages do not require reading skills but only basic ability to receive phone calls. This finding is consistent with previous studies that demonstrated the preference for voice messages among the rural population in Bangladesh and Cambodia, who also had low rates of reading literacy $[26,27]$. Thus, we believe that voice messages have great potential to deliver interventions, especially among populations with low socioeconomic status.

Message-based interventions have been increasingly applied to promote chronic disease management. However, less attention had been paid to content design than its effectiveness. A number of studies have tested the effectiveness of phone-based interventions implemented among various populations worldwide $[25,28,29]$, but only a few studies have described in detail the development process of message-based interventions and their lessons learned. Studies have found insufficient use of behavior change theories in mHealth messages and lack of involvement of the target population in the design process [30]. The modest effect and inconsistent results of message-based interventions suggest that we cannot overlook the design process. In our study, the health belief model [16] and the transtheoretical model (stage of change) [21] were embedded in the message contents by emphasizing the perceived threat of poor adherence to medication use, improving their perceived benefits in behavior change in line with the secondary prevention recommendation, providing them cues to action and encouraging 
their maintenance throughout different stages. In addition, considering the education level and health literacy of stroke patients in rural China, we did not involve our target population in the initial drafting of messages as some other studies did [31], but instead, we conducted interviews to understand their needs, tested their acceptance through a pilot study, and refined the messages based on their feedback.

Our study also revealed that the design of messages should adequately consider the local context and characteristics of the target audience. We found that message structure, language, complexity and relevance, and repetition are factors that influence patients' acceptance and understanding. This finding is in line with some of the previous studies. For example, Muench and Baumel [32] analyzed the components of digital triggers in messages and differentiated triggers into 5 elements, including the sender, delivery approach, time of delivery, frequency, and trigger contents. Our study results also showed that a reliable sender, an accepted form of the message dispatch, optimal timing based on patients' daily routine, and simple but relevant key messages were essential for the acceptance of message-based interventions. In addition, we also discovered certain factors that are specific to voice messages. For example, the speed of audio playback, the pattern of repetition, and the use of dialect may also improve audiences' understanding of message contents [26].

\section{Limitations and Strengths}

Our study has some limitations. First, in this pilot study, the acceptance of messages was measured using a self-designed short survey, rather than actual statistics from the message dispatch system in the number of messages received and reviewed. Thus, self-report bias could be introduced, as participants may have overrated their acceptance and understanding of messages when interviewed by village doctors because of recall or social desirability bias. In addition, although the questionnaire was designed based on previous studies in China, we did not conduct reliability and validity testing for the questionnaire; thus, we were not able to rule out all potential measurement errors from the study. Second, the participants involved in our contextual research and pilot study were conveniently sampled with a relatively small sample size based on set inclusion criteria. For example, more than $60 \%$ of our participants were male, and such proportion is higher than the proportion in general stroke patients, although the nationwide epidemiological study found a higher age-specific prevalence of stroke among men than that among women for the age groups of above 40 years [1]. Although participants may not be fully representative of all stroke patients in rural areas of China, we believe that the views they shared were common among stroke patients in rural China.

Our study also has several strengths. First, we have applied multiple methodologies, including literature review, expert consultation, qualitative in-depth interviews, and a pilot study, including a quantitative survey and personal interviews. By doing so, we were able to ensure a deeper involvement of the target population in the study design and gain a more comprehensive understanding of their needs, acceptance, and preferences. Second, the messages were developed by researchers and verified by health care professionals and village doctors. Such collaboration ensured that the messages were designed based on the clinical evidence and behavior change theories with conscientious consideration of local context. By applying these strategies, the contents of messages could be made reliable, feasible, and understandable. Third, the results of the initial design and pilot study were incorporated into the refinement of both the final content and delivery algorithm, potentially ensuring better acceptance and effectiveness of the message-based intervention.

\section{Conclusions}

In summary, our study demonstrates the potential of using voice message interventions to improve chronic disease prevention and management among people with low education level in resource-limited settings. The development process indicates the importance of contextualization, which includes involving the target audience early and considering their preference and characteristics in the design process. The findings on the preference of participants for voice messages and the potential factors related to the acceptance add new evidence to the literature. These findings have general implications beyond stroke care in rural China and will be informative to other researchers who plan to develop message-based interventions for other disease conditions or in other research settings.

We recommend future studies to describe the message development procedures so that researchers could have better insight on the underlining mechanisms of the message design and the contextual environment that enabled the intervention implementation, which will facilitate the construction of the evidence based on the impact of the message-based interventions. In addition, more studies are needed to understand further the generalizability of the key aspects of message optimization that we found through our study among other populations. With such knowledge, we could better design the content and dispatching algorithms of the message-based interventions with higher adoption and maintenance.

\section{Acknowledgments}

The authors would like to thank Yun Zhou, Zixiao Li, Yilong Wang, Ninghua Wang, Bin Xie, Jianmin Yao, Mobai Hou, Li Wang, Lihui Hu, Bichuan Lu, Pengfei Dai, and Guodong Fan, who were involved in the verification of the messages. The authors also appreciate all stroke patients, caregivers, village doctors, township physicians, and county managers, who have provided advice and feedback about the mHealth message system to the research team throughout the study. The authors would also like to thank the leaders and staff from the Nanhe County Center for Disease Prevention and Control, Nanhe County People's Hospital, and the Nanhe County Health and Family Planning Commission, who supported the implementation of the study. The study was jointly funded by the Medical Research Council, Wellcome Trust, the Economic and Social Research Council, and the Department 
for International Development of the United Kingdom (grant number: MR/N015967/1). These sponsors have no role in either the preparation or approval of the manuscript.

\section{Authors' Contributions}

LLY is the principal investigator of the study and guided the design, refinement, and manuscript writing process. EG and WG drafted the manuscript, and other coauthors contributed to the manuscript revision and approved the final version for publication. EL and LT conducted the literature review of existing message banks; EG and WG conducted data analysis; LT, JD, CS, and YY drafted the initial messages for the pilot study; and EL, LZ, PB, EG, WG, and LLY were involved in the message refinements. All authors critically reviewed and approved the content of the paper.

\section{Conflicts of Interest}

None declared.

\section{Multimedia Appendix 1}

Key searching terms, procedure, and findings from the literature review on the existing message banks.

[DOCX File, 92 KB-Multimedia Appendix 1]

\section{Multimedia Appendix 2}

Examples of messages.

[DOCX File, 14 KB-Multimedia Appendix 2]

\section{References}

1. Wang W, Jiang B, Sun H, Ru X, Sun D, Wang L, NESS-China Investigators. Prevalence, incidence, and mortality of stroke in China: results from a nationwide population-based survey of 480687 adults. Circulation 2017 Feb 21;135(8):759-771. [doi: 10.1161/CIRCULATIONAHA.116.025250] [Medline: 28052979]

2. Wang L, Liu J, Yang Y, Peng B, Yilong W. The prevention and treatment of stroke still face huge challenges-brief report on stroke prevention and treatment in China, 2018. Chin Circ J 2019;34(2):105-119 [FREE Full text]

3. Liu L, Liu J, Wang Y, Wang D, Wang Y. Substantial improvement of stroke care in China. Stroke 2018 Dec;49(12):3085-3091. [doi: 10.1161/STROKEAHA.118.022618] [Medline: 30571434]

4. World Health Organization. Prevention of Recurrent Heart Attacks and Strokes in Low and Middle Income Populations: Evidence-based Recommendations for Policy-makers and Health Professionals. Geneva: World Health Organization; 2003.

5. Chen Y, Li L, Zhang Q, Clarke R, Chen J, Guo Y, China Kadoorie Biobank Study. Use of drug treatment for secondary prevention of cardiovascular disease in urban and rural communities of China: China Kadoorie Biobank study of 0.5 million people. Int J Cardiol 2014 Mar 1;172(1):88-95 [FREE Full text] [doi: 10.1016/j.ijcard.2013.12.065] [Medline: 24461961]

6. Jiang Y, Yang X, Li Z, Pan Y, Wang Y, Wang Y, et al. Persistence of secondary prevention medication and related factors for acute ischemic stroke and transient ischemic attack in China. Neurol Res 2017 Jun;39(6):492-497. [doi: 10.1080/01616412.2017.1312792] [Medline: 28420316]

7. Shi Y, Yi H, Zhou H, Zhou C, Xue H, Rozelle S, et al. The quality of primary care and correlates among grassroots providers in rural China: a cross-sectional standardised patient study. The Lancet 2017 Dec;390:S16. [doi: 10.1016/S0140-6736(17)33154-9]

8. Orr JA, King RJ. Mobile phone SMS messages can enhance healthy behaviour: a meta-analysis of randomised controlled trials. Health Psychol Rev 2015;9(4):397-416. [doi: 10.1080/17437199.2015.1022847] [Medline: 25739668]

9. Yasmin F, Banu B, Zakir SM, Sauerborn R, Ali L, Souares A. Positive influence of short message service and voice call interventions on adherence and health outcomes in case of chronic disease care: a systematic review. BMC Med Inform Decis Mak 2016 Apr 22;16:46 [ [FREE Full text] [doi: 10.1186/s12911-016-0286-3] [Medline: 27106263]

10. Beratarrechea A, Lee A, Willner J, Jahangir E, Ciapponi A, Rubinstein A. The impact of mobile health interventions on chronic disease outcomes in developing countries: a systematic review. Telemed J E Health 2014 Jan;20(1):75-82 [FREE Full text] [doi: 10.1089/tmj.2012.0328] [Medline: 24205809]

11. Kamal AK, Shaikh Q, Pasha O, Azam I, Islam M, Memon AA, et al. A randomized controlled behavioral intervention trial to improve medication adherence in adult stroke patients with prescription tailored Short Messaging Service (SMS)-SMS4Stroke study. BMC Neurol 2015 Oct 21;15:212 [FREE Full text] [doi: 10.1186/s12883-015-0471-5] [Medline: 26486857]

12. Yang X, Kovarik C. A systematic review of mobile health interventions in China: identifying gaps in care. J Telemed Telecare 2019 Jul 18:1357633X19856746. [doi: 10.1177/1357633X19856746] [Medline: 31319759]

13. Thakkar J, Kurup R, Laba T, Santo K, Thiagalingam A, Rodgers A, et al. Mobile telephone text messaging for medication adherence in chronic disease: a meta-analysis. JAMA Intern Med 2016 Mar;176(3):340-349. [doi: 10.1001/jamainternmed.2015.7667] [Medline: 26831740] 
14. Sahin C, Courtney KL, Naylor PJ, E Rhodes R. Tailored mobile text messaging interventions targeting type 2 diabetes self-management: a systematic review and a meta-analysis. Digit Health 2019;5:2055207619845279 [FREE Full text] [doi: 10.1177/2055207619845279] [Medline: 31041110]

15. Anstey Watkins J, Goudge J, Gómez-Olivé FX, Huxley C, Dodd K, Griffiths F. mHealth text and voice communication for monitoring people with chronic diseases in low-resource settings: a realist review. BMJ Glob Health 2018;3(2):e000543 [FREE Full text] [doi: 10.1136/bmjgh-2017-000543] [Medline: 29527356]

16. Champion V, Skinner C. The health belief model. In: Glanz K, Rimer BK, Viswanath K, editors. Health Behavior and Health Education: Theory, Research, Practice. Fourth Edition. San Francisco: Josseybass; 2008:45-65.

17. Diez-Canseco F, Zavala-Loayza JA, Beratarrechea A, Kanter R, Ramirez-Zea M, Rubinstein A, et al. Design and multi-country validation of text messages for an mHealth intervention for primary prevention of progression to hypertension in Latin America. JMIR Mhealth Uhealth 2015 Feb 18;3(1):e19 [FREE Full text] [doi: 10.2196/mhealth.3874] [Medline: 25693595]

18. Gong E, Gu W, Sun C, Turner EL, Zhou Y, Li Z, et al. System-integrated technology-enabled model of care to improve the health of stroke patients in rural China: protocol for SINEMA-a cluster-randomized controlled trial. Am Heart J 2019 Jan;207:27-39. [doi: 10.1016/j.ahj.2018.08.015] [Medline: 30408621]

19. China Statistic Press. Hebei Economic Yearbook 2016. 2016. URL: http://www.hetj.gov.cn/res/nj2016/indexch.htm [accessed 2019-01-30]

20. Xu G, Ma M, Liu X, Hankey GJ. Is there a stroke belt in China and why? Stroke 2013 Jul;44(7):1775-1783. [doi: 10.1161/STROKEAHA.113.001238] [Medline: 23674531]

21. Prochaska J, Redding C, Evers K. The transtheoretical model and stages of change. In: Glanz K, Rimer BK, Viswanath K, editors. Health Education and Health Behavior: Theory, Research, Practice. San Francisco: JosseyBass; 2015:125-148.

22. Yan LL, Fang W, Delong E, Neal B, Peterson E, Huang Y, et al. Population impact of a high cardiovascular risk management program delivered by village doctors in rural China: design and rationale of a large, cluster-randomized controlled trial. BMC Public Health 2014 Apr 11;14:345 [FREE Full text] [doi: 10.1186/1471-2458-14-345] [Medline: 24721435]

23. Zhou B, Zhang J, Zhao Y, Li X, Anderson CS, Xie B, et al. Caregiver-delivered stroke rehabilitation in rural China. Stroke 2019 Jul;50(7):1825-1830. [doi: 10.1161/STROKEAHA.118.021558] [Medline: $\underline{31177978]}$

24. Braun V, Clarke V. Using thematic analysis in psychology. Qual Res Psychol 2006;3(2):77-101. [doi: 10.1191/1478088706qp063oa]

25. Adler AJ, Martin N, Mariani J, Tajer CD, Owolabi OO, Free C, et al. Mobile phone text messaging to improve medication adherence in secondary prevention of cardiovascular disease. Cochrane Database Syst Rev 2017 Apr 29;4:CD011851 [FREE Full text] [doi: 10.1002/14651858.CD011851.pub2] [Medline: 28455948]

26. Eckersberger E, Pearson E, Andersen K, Hossain A, Footman K, Biswas K, et al. Developing mHealth messages to promote postmenstrual regulation contraceptive use in Bangladesh: participatory interview study. JMIR Mhealth Uhealth 2017 Dec 14;5(12):e174 [FREE Full text] [doi: 10.2196/mhealth.6969] [Medline: 29242175]

27. Bullen PA. Operational challenges in the Cambodian mHealth revolution. J Mob Technol Med 2013;2(2):20-23. [doi: 10.7309/jmtm.2.2.5]

28. Kannisto K, Koivunen M, Välimäki MA. Use of mobile phone text message reminders in health care services: a narrative literature review. J Med Internet Res 2014 Oct 17;16(10):e222 [FREE Full text] [doi: 10.2196/jmir.3442] [Medline: $\underline{25326646]}$

29. Marcolino MS, Oliveira JA, D'Agostino M, Ribeiro AL, Alkmim MB, Novillo-Ortiz D. The impact of mHealth interventions: systematic review of systematic reviews. JMIR Mhealth Uhealth 2018 Jan 17;6(1):e23 [FREE Full text] [doi: 10.2196/mhealth.8873] [Medline: 29343463]

30. Cho Y, Lee S, Islam S, Kim SY. Theories applied to m-Health interventions for behavior change in low- and middle-income countries: a systematic review. Telemed J E Health 2018 Oct;24(10):727-741 [FREE Full text] [doi: 10.1089/tmj.2017.0249] [Medline: 29437546]

31. Toefy Y, Skinner D, Thomsen S. 'Please Don't Send Us Spam!' A participative, theory-based methodology for developing an mHealth intervention. JMIR Mhealth Uhealth 2016 Aug 17;4(3):e100 [FREE Full text] [doi: 10.2196/mhealth.6041] [Medline: 27535589]

32. Muench F, Baumel A. More than a text message: dismantling digital triggers to curate behavior change in patient-centered health interventions. J Med Internet Res 2017 May 26;19(5):e147 [FREE Full text] [doi: 10.2196/jmir.7463] [Medline: $\underline{28550001]}$

\section{Abbreviations}

mHealth: mobile health

SINEMA: System-Integrated Technology-Enabled Model of Care 
Edited by G Eysenbach; submitted 03.08.19; peer-reviewed by T Alessa, L Shen; comments to author 18.09.19; revised version received 29.09.19; accepted 30.09.19; published 17.12.19

Please cite as:

Gong E, Gu W, Luo E, Tan L, Donovan J, Sun C, Yang Y, Zang L, Bao P, Yan LL

Development and Local Contextualization of Mobile Health Messages for Enhancing Disease Management Among Community-Dwelling Stroke Patients in Rural China: Multimethod Study

JMIR Mhealth Uhealth 2019;7(12):e15758

URL: https://mhealth.jmir.org/2019/12/e15758

doi: $\underline{10.2196 / 15758}$

PMID: 31845901

(CEnying Gong, Wanbing Gu, Erdan Luo, Liwei Tan, Julian Donovan, Cheng Sun, Ying Yang, Longkai Zang, Peng Bao, Lijing L Yan. Originally published in JMIR mHealth and uHealth (http://mhealth.jmir.org), 17.12.2019. This is an open-access article distributed under the terms of the Creative Commons Attribution License (https://creativecommons.org/licenses/by/4.0/), which permits unrestricted use, distribution, and reproduction in any medium, provided the original work, first published in JMIR mHealth and uHealth, is properly cited. The complete bibliographic information, a link to the original publication on http://mhealth.jmir.org/, as well as this copyright and license information must be included. 